\title{
Antibiotic sensitivity pattern of common bacterial pathogens in NICU and neonatal ward in Hamedan province of Iran
}

\author{
Alireza Monsef ${ }^{1}$, Fatemeh Eghbalian ${ }^{2 *}$ \\ ${ }^{1}$ Pathology Department, Hamadan University of Medical Sciences, Hamadan, Iran \\ ${ }^{2}$ Pediatric Department, Hamadan University of Medical Sciences, Hamadan, Iran; ${ }^{*}$ Corresponding Author: eghbalian_fa@yahoo.com
}

Received 15 January 2010; revised 5 February 2010; accepted 8 February 2010.

\begin{abstract}
Bacterial pathogens and drug resistance are different in hospitals of each country. In this study we determined bacterial path- ogens and drug sensitivity in the neonatal ward and neonatal intensive care unit (NICU) in Ekbatan hospital in Hamedan. This cross-sectional descriptive study was done on $\mathbf{1 1 5 0}$ hospitalized neonates in neonatal and NICU wards of Ekbatan hospital of the Hamadan university of medical sciences from September 2004 to September 2006. Blood, cerebrospinal fluid (CSF), urine, stool, eye excretion, synovial fluid, umbilical secretion and ascitic fluid were evaluated. Positive cultures were evaluated for antibiotic resistance with disk diffusion test methed. All of the data in questionnaires was analyzed with SPSS 13. Cultures including blood, urine, CSF , stool, eye excretion, synovial fluid, umbilical secretion and ascitic fluid was done in 417 neonates (833 cultures). These cultures were including: urine, 323 cases $(38.8 \%)$ blood 293 cases $(35.2 \%)$, CSF 180 cases $(21.6 \%)$, stool 17 cases $(2 \%)$, eye secretion 16 cases $(1.9 \%)$ and other secretions (synovial, umbilical, etc) 4 cases $(0.5 \%)$. The cultures were positive in 105 cases $(25.2 \%)$. 60 male neonates $(57.1 \%)$ and 45 female neonates $(42.9 \%)$ were culture positive. The most common microorganisms were $\mathrm{E}$ coli $66.7 \%$ (70 cases), Klebsiella $10.5 \%$ (11 cases). Drug resistance was high in these microorganisms. The most common microorganisms were Ecoli and klebsiella. Drug resistance was high in the isolated microorganisms.
\end{abstract}

Keywords: Drug Resistance; Neonate; Bacterial Infections

\section{INTRODUCTION}

There has been high incidence of antimicrobial resistance in bacterial infections in different parts of a country and also in any hospital [1-3]. Different mechanisms are involved in drug resistance of microorganisms. It may be genetic or non genetic in origin [4]. Widespread use of broadspectrum antibiotics is the most important factor, so antibiotic control policy has great importance in drug resistance control [5]. The incidence of infections in hospitalized neonates is very high. After widespread use of antibiotics in agriculture industry and medicine from 1950, antibiotics resistance in common pathogenic agents had increasingly emerged [6]. In developed countries constant investigation in this field had done for identifying antibiotic resistance pattern. Recently, the spectrum and resistance of the pathogenic bacteria have constantly changed year after year because of wide application of antimicrobial drugs [5-9]. It is necessary to treat neonatal infections by empirical use of antimicrobial drugs as soon as possible to reduce the mortality of them. It is based on the knowledge of epidemiology of bacterial susceptibility pattern in each area [6-15]. This study had done for identifying antimicrobial susceptibility pattern in a western province of Iran in neonatal ward to help the treatment of infected neonates.

\section{MATERIAL AND METHOD}

This cross-sectional descriptive study was done on 1150 hospitalized neonates in neonatal and neonatal intensive care unit (NICU) wards of Ekbatan hospital of the Hamadan University of Medical Sciences from September 2004 to September 2006. Approval from Hamadan University of Medical Sciences was obtained prior the study. All of the samples that had sent for bacteriological analysis entered the study. They included blood, cerebro-spinal fluid (CSF), urine, stool, eye excretion, syno- 
vial fluid, umbilical excretion and peritoneal fluid.

Urine samples in neonates had obtained by suprapubic method. In case of bacterial growth, identification of the bacteria had done and antibiogram by disc diffusion method had performed (Karbibauer method, Padtan Teb antibiotic disc Company).

The quality control modalities had done on the National Reference Laboratory of Health standards. The antibiotics susceptibility test results had entered the questionnaires. The data had analyzed by SPSS software (version 13).

\section{RESULTS}

A total of 1150 hospitalized neonates entered the study. There were 417 cultured samples, 239 cases $(56.1 \%)$ were male and 183 cases $(43.9 \%)$ were female.

The mean age of neonates was $11.3 \pm 9.3$ days, $(1$ to 30 days).

We found 833 cultures in 417 cases, they included: urine culture $322(38.7 \%)$, blood culture $293(35.2 \%)$, CSF culture $180(21.6 \%)$, stool culture 17 (2\%), eye excretion $16(1.9 \%)$, others (synovial fluid, cord excretion ...) $5(0.6 \%)$.

In this study $25.5 \%$ of the cultures were positive and $74.8 \%$ were negative. $57.1 \%$ (60 neonates) of positive cultures were male and remaining 42.9\% (45 neonates) were female.

Eye excretion was the most positive culture (81.2\%). (Table 1) Table 1 shows the results of cultures.

The most frequent isolated microorganisms were E.coli $66.7 \%$ (70 cases) and Klebciella 10.5\% (11 cases) in decreasing order (Figure 1).

Table 2 shows the frequency of isolated bacteria in the culture.

Table 3 shows the sensitivity and resistance pattern of bacteria cultured in urine culture. Tables 4 and 5 reveal of the bacterial susceptibility tests in the neonates.

\section{DISCUSSION}

Bacterial infection is still prevalent in newborns and it is a major medical problem [1-3]. According to the european countries reports, its prevalence had not changes in previous half decade, whereas bacterial etiologic agents had changed. From 1928 to 1932 beta hemolytic streptococci with $38 \%$ prevalence and staphylococcus aurous with $28 \%$ were the most frequent causes of septicemia, although the former is not so prevalent yet [13-14]. In the present study Escherichia coli (Ecoli) was $66.7 \%$ and Klebciella was $10.5 \%$, they were the more frequent bacteria isolated from urine, blood and eye excretion cul tures. Ecoli was the most frequent isolated bacteria from urine, eye excretion and blood cultures in an order of
Table 1. Abundance distribution of positive cultures according to the source of culture in hospitalized neonates.

\begin{tabular}{lcc}
\hline \multirow{2}{*}{ Source of culture } & \multicolumn{2}{c}{ Culture results } \\
\cline { 2 - 3 } & $\begin{array}{l}\text { Negative } \\
(\%) ~ N O\end{array}$ & $\begin{array}{l}\text { Positive } \\
(\%) ~ N O\end{array}$ \\
\hline Urine $(\mathrm{N}=323)$ & $253(78.3)$ & $70(\mathbf{2 1 . 7 )}$ \\
Blood $(\mathrm{N}=293)$ & $278(94.9)$ & $15(5.1)$ \\
CSF $(\mathrm{N}=180)$ & $180(100)$ & - \\
Stool $(\mathrm{N}=17)$ & $14(82.4)$ & $3(17.6)$ \\
Eye secretions $(\mathrm{N}=16)$ & $3(18.8)$ & $13(81.2)$ \\
Other body fluid $(\mathrm{N}=5)$ & $1(20)$ & $4(80)$ \\
\hline
\end{tabular}

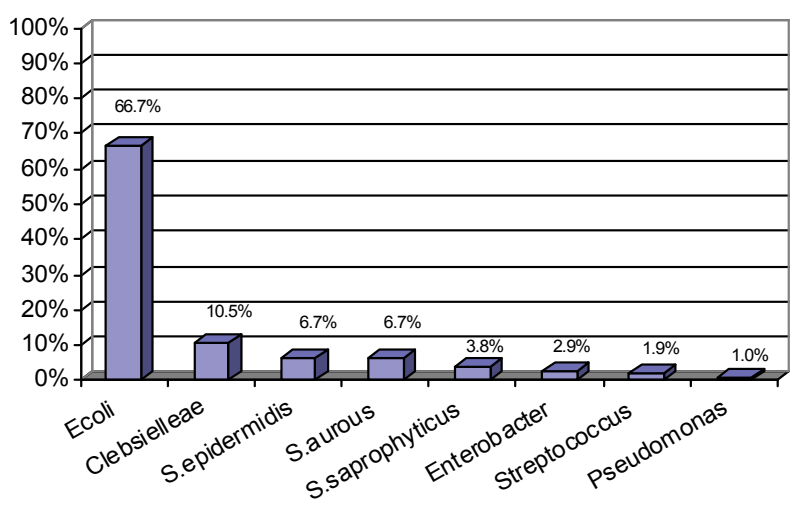

Figure 1. Abundance distribution of isolated microorganisms in culture positive newborns.

Table 2. Abundance distribution of isolated microorganisms according to the source of culture in hospitalized neonates.

\begin{tabular}{lccccc}
\hline & \multicolumn{5}{c}{ Source of culture } \\
\cline { 2 - 6 } $\begin{array}{l}\text { Isolated } \\
\text { microorganisms }\end{array}$ & $\begin{array}{c}\text { Urine } \\
(\mathrm{N}=70)\end{array}$ & $\begin{array}{c}\text { Blood } \\
(\mathrm{N}=15)\end{array}$ & $\begin{array}{c}\text { Stool } \\
(\mathrm{N}=3)\end{array}$ & $\begin{array}{c}\text { Eye } \\
\text { secretions } \\
(\mathrm{N}=13)\end{array}$ & $\begin{array}{c}\text { Other } \\
\text { body } \\
\text { fluid } \\
(\mathrm{N}=4)\end{array}$ \\
\hline E.coli & $(\% 77.1) 54$ & $(\% 53.3) 8$ & - & $(46.2 \%) 6$ & $(50 \%) 2$ \\
Klebsiella & $(\% 12.9) 9$ & $(\% 6.7) 1$ & $(33.3) 1$ & - & - \\
S.Saprophyticus & $(\% 5.7) 4$ & - & - & - & - \\
Enterobacter & $(\% 1.4) 1$ & $(\% 6.7) 1$ & $(33.3) 1$ & & - \\
S.Aurous & $(\% 2.9) 2$ & $(\% 6.7) 1$ & - & $(\% 23.1) 3$ & $(\% 25) 1$ \\
S.Epidermidis & - & $(\% 26.7) 4$ & - & $(\% 23.1) 3$ & - \\
pseudomonas & - & - & $(33.3) 1$ & & - \\
Streptocucus & - & - & - & $(\% 7.7) 1$ & $(\% 25) 1$ \\
\hline
\end{tabular}


$77.1 \%, 46.2 \%$ and $53.6 \%$ respectively. These findings are consistent with the results of Eghbalian et al. study [15]. Yalaz et al. in Turkey studied 909 newborns, 9.1\% of them had sepsis, the isolated bacteria were: coagulase negative staphylococcus $31.3 \%$, fungi $19.2 \%$, staphylococcus aurous 13\%, Klebsiella Pneumonia 10.5\% in decreasing order [11].

Another study of Aurangzeb et al. at 2003 revealed 112 hospitalized newborns as sepsis, 67\% had positive blood culture and E.coli was the most frequent cause with $77.1 \%$ frequency [12]. Bacterial meningitis has various ethologic factors and majority of authors believe that its agents varies according to age and geographic distribution $[1,3,15,16]$. In present study we did not found any positive cerebrospinal fluid culture in the newborns. In our study E.coli, the most prevalent isolated microorganism, shows high degree resistance to cephalosporins. It showed $75.9 \%$ resistance in urine culture to Ceftriaxone, and 60\% to Ceftizoxime (Table 3).
When we separated the E.coli from the blood and eye excretion cultures, most of them were resistant to Cephalosporins specially to Ceftriaxone. Also E.coli was resistant to majority of aminoglycozid antibiotics including Amikacin, Gentamycin and Tobramycin. (Tables 4, 5) In our study the resistance of E.coli to the Ciprofloxacin, Nalidixic acid, Nitrofurantoin and Cotrimoxazol were in a decreasing order (Tables 3, 4, 5) .These findings are consistent with the results of a similar study [15]. Aurangzeb et al. in a similar study showed high degree resistance of gram negative bacteria to conventional antibiotics: $79.3 \%$ to Ampicillin, $74.6 \%$ to Amoxicillin, $71.6 \%$ to Ceftazidime, $50.2 \%$ to Cefotaxime, $43.2 \%$ to Gentamycin, 34.3 to Tobramycin, $23.6 \%$ to Imipenem, $22.3 \%$ to Amikacin and $11.9 \%$ to Ciprofloxacin [12]. Also staphylococcus aurous showed $75 \%$ resistance to Ampicillin [12]. The present study revealed high percentage resistance of staphylococcus aurous to cephalosporin and other broad spectrum antibiotics.

Table 3. Percentage of sensitivity and resistance of isolated bacteria from positive urine culture in hospitalized neonates.

\begin{tabular}{|c|c|c|c|c|c|c|c|c|c|c|}
\hline \multicolumn{10}{|c|}{ Microorganisms } & \multirow{3}{*}{ Antibiotic } \\
\hline \multicolumn{2}{|c|}{ S.Aurous } & \multicolumn{2}{|c|}{ Enterobacter } & \multicolumn{2}{|c|}{ S.Saprophyticus } & \multicolumn{2}{|c|}{ Clebsiellea } & \multicolumn{2}{|c|}{ E.coli } & \\
\hline Resistance & Sencetive & Resistance & Sencetive & Resistance & Sencetive & Resistance & Sencetive & Resistance & Sensitive & \\
\hline --- & --- & --- & --- & --- & --- & $6(\% 100)$ & 0 & $22(\% 9 / 75)$ & $7(\% 1 / 24)$ & Ceftriaxon \\
\hline $1(\% 100)$ & 0 & 0 & $1(\% 100)$ & $3(\% 100)$ & 0 & $4(\% 7 / 66)$ & $2(\% 3 / 33)$ & $28(\% 1 / 65)$ & $15(\% 9 / 34)$ & Amikacin \\
\hline--- & --- & 0 & $1(\% 100)$ & 0 & $1(\% 100)$ & 0 & $6(\% 100)$ & $6(\% 2 / 18)$ & $27(\% 8 / 81)$ & Ciprofloxacin \\
\hline 0 & $1(\% 100)$ & $1(\% 100)$ & 0 & $3(\% 100)$ & 0 & $6(\% 75)$ & $2(\% 25)$ & $32(\% 4 / 74)$ & $11(\% 6 / 25)$ & Jentamycin \\
\hline --- & --- & --- & --- & -- & --- & $1(\% 100)$ & 0 & $12(\% 7 / 85)$ & $2(\% 3 / 14)$ & Tobramycin \\
\hline--- & --- & -- & --- & -- & --- & $2(\% 100)$ & 0 & $9(\% 60)$ & $6(\% 40)$ & Trimetoprim \\
\hline 0 & $1(\% 100)$ & 0 & $1(\% 100)$ & $1(\% 100)$ & 0 & $6(\% 100)$ & 0 & $21(\% 60)$ & $14(\% 40)$ & Ceftixocim \\
\hline $1(\% 100)$ & 0 & 0 & $1(\% 100)$ & $2(\% 7 / 66)$ & $1(\% 3 / 33)$ & $5(\% 4 / 71)$ & $2(\% 6 / 28)$ & $13(\% 3 / 33)$ & $26(\% 7 / 66)$ & Nitrofurantoin \\
\hline--- & --- & --- & --- & 0 & $2(\% 100)$ & $2(\% 3 / 33)$ & $4(\% 7 / 66)$ & $9(\% 36)$ & $16(\% 64)$ & Cotrimoxazol \\
\hline--- & --- & $1(\% 100)$ & 0 & $1(\% 50)$ & $1) 50(\%$ & $4(\% 100)$ & 0 & $15(\% 60)$ & $10(\% 40)$ & Cefotacxim \\
\hline --- & --- & --- & --- & $2(\% 100)$ & 0 & --- & --- & --- & --- & Vancomycine \\
\hline $1(\% 100)$ & 0 & --- & --- & $2(\% 100)$ & 0 & $1(\% 100)$ & 0 & $5(\% 50)$ & $5(\% 50)$ & Cephalexin \\
\hline--- & -- & $1(\% 100)$ & 0 & -- & -- & --- & -- & $3(\% 60)$ & $2(\% 40)$ & Ampicillin \\
\hline --- & --- & --- & --- & --- & --- & --- & --- & 0 & $4(\% 100)$ & Cephalotin \\
\hline
\end{tabular}


Table 4. Percentage of sensitivity and resistance of isolated bacteria from positive blood culture in hospitalized neonates.

\begin{tabular}{|c|c|c|c|c|c|c|c|c|c|c|}
\hline \multicolumn{10}{|c|}{ Microorganisms } & \multirow{3}{*}{ Antibiotic } \\
\hline \multicolumn{2}{|c|}{ S.Aurous } & \multicolumn{2}{|c|}{ Enterobacter } & \multicolumn{2}{|c|}{ S.Epidermidis } & \multicolumn{2}{|c|}{ klebsiellea } & \multicolumn{2}{|c|}{ E.coli } & \\
\hline Resistance & Sencetive & Resistance & Sencetive & Resistance & Sencetive & Resistance & Sencetive & Resistance & Sensitive & \\
\hline--- & --- & --- & --- & 0 & $1(\% 100)$ & --- & --- & $4(\% 100)$ & 0 & Ceftriaxon \\
\hline--- & --- & 0 & $1(\% 100)$ & 0 & $1(\% 100)$ & $1(\% 100)$ & 0 & $3(\% 50)$ & $3(\% 50)$ & Amikacin \\
\hline --- & --- & 0 & $1(\% 100)$ & 0 & $1(\% 100)$ & --- & --- & 0 & $5(\% 100)$ & Ciprofloxacin \\
\hline $1(\% 100)$ & 0 & 0 & $1(\% 100)$ & 0 & $1(\% 100)$ & $1(\% 100)$ & 0 & $3(\% 60)$ & $2(\% 40)$ & Gentamycin \\
\hline--- & --- & 0 & $1(\% 100)$ & --- & --- & 0 & $1(\% 100)$ & $1(\% 25)$ & $3(\% 75)$ & Nalidixic acid \\
\hline--- & --- & --- & --- & $1(\% 50)$ & $1(\% 50)$ & 0 & $1(\% 100)$ & $2(\% 50)$ & $2(\% 50)$ & Ceftizoxime \\
\hline--- & --- & 0 & $1(\% 100)$ & --- & --- & $1(\% 100)$ & 0 & $2(\% 28 / 6)$ & $5(\% 71 / 4)$ & Tetracyclin \\
\hline--- & --- & $1(\% 100)$ & 0 & 0 & $1(\% 100)$ & $1(\% 100)$ & 0 & $3(\% 42 / 9)$ & $4(\% 57 / 1)$ & Nitrofurantoin \\
\hline--- & --- & $1(\% 100)$ & 0 & --- & --- & 0 & $1(\% 100)$ & $2(\% 50)$ & $2(\% 50)$ & Cotrimoxazol \\
\hline--- & --- & --- & --- & $3(\% 100)$ & 0 & --- & --- & --- & --- & Cloxacillin \\
\hline $1(\% 100)$ & 0 & --- & --- & 0 & $1(\% 100)$ & $1(\% 100)$ & 0 & $3(\% 6)$ & $2(\% 40)$ & Cefotacxim \\
\hline--- & --- & --- & --- & 0 & $4(\% 100)$ & --- & --- & --- & --- & Vancomycine \\
\hline
\end{tabular}

Table 5. Percentage of sensitivity and resistance of isolated bacteria from positive eye excretions culture in hospitalized neonates.

\begin{tabular}{|c|c|c|c|c|c|c|c|c|}
\hline \multicolumn{8}{|c|}{ Microorganisms } & \multirow{3}{*}{ Antibiotic } \\
\hline \multicolumn{2}{|c|}{ Streptocucus } & \multicolumn{2}{|c|}{ S.Epidermidis } & \multicolumn{2}{|c|}{ S.Aurous } & \multicolumn{2}{|c|}{ E.coli } & \\
\hline Resistance & Sencetive & Resistance & Sencetive & Resistance & Sencetive & Resistance & Sencetive & \\
\hline--- & --- & --- & --- & $(\% 100) 1$ & 0 & $(\% 100) 4$ & 0 & Ceftriaxon \\
\hline$(\% 100) 1$ & 0 & $(\% 100) 1$ & 0 & $(\% 50) 1$ & $(\% 50) 1$ & $(\% 40) 2$ & $(\% 60) 3$ & Amikacin \\
\hline--- & --- & $(\% 100) 1$ & 0 & --- & --- & $(\% 66 / 7) 2$ & $(\% 33 / 3) 1$ & Ciprofloxacin \\
\hline$(\% 100) 1$ & 0 & $(\% 100) 1$ & 0 & 0 & $(\% 100) 1$ & $(\% 66 / 7) 2$ & $(\% 33 / 3) 1$ & Gentamycin \\
\hline--- & --- & $(\% 50) 1$ & $(\% 50) 1$ & $(\% 100) 1$ & 0 & $(\% 75) 3$ & $(\% 25) 1$ & Ceftixocim \\
\hline --- & --- & --- & --- & --- & --- & 0 & $(\% 100) 3$ & Tetracyclin \\
\hline--- & --- & 0 & $(\% 100) 1$ & $(\% 100) 1$ & 0 & --- & --- & Amoxicillin \\
\hline--- & --- & $(\% 100) 2$ & 0 & $(\% 100) 1$ & 0 & 0 & $(\% 100) 1$ & Cloxacillin \\
\hline--- & --- & $(\% 50) 1$ & $(\% 50) 1$ & $(\% 100) 2$ & 0 & --- & --- & Erythromycin \\
\hline 0 & $(\% 100) 1$ & $(\% 100) 1$ & 0 & $(\% 50) 1$ & $(\% 50) 1$ & $(\% 75) 3$ & $(\% 25) 1$ & Cefotacxim \\
\hline 0 & $(\% 100) 1$ & 0 & $(\% 100) 3$ & 0 & $(\% 100) 1$ & --- & --- & vancomycin \\
\hline--- & --- & 0 & $(\% 100) 1$ & $(\% 50) 1$ & $(\% 50) 1$ & $(\% 100) 1$ & 0 & Cephalexin \\
\hline --- & --- & $(\% 50) 1$ & & $(\% 100) 1$ & 0 & $(\% 100) 2$ & 0 & Ampicillin \\
\hline--- & --- & --- & --- & 0 & $(\% 100) 1$ & --- & --- & Chloramphenicol \\
\hline
\end{tabular}




\section{CONCLUSIONS}

Our experience showed that gram-negative bacteria were the most prevalent cause of infections in neonates in our hospital. E.coli and Klebsiella were the most frequent bacteria and majority of them were resistant to broad spectrum antibiotics. Drug resistance to conventional antibiotics is a common problem and it grows readily. Antimicrobials must be administered conservatively according to epidemiologic studies in the region, with confirmed indications, and based on the results of susceptibility tests.

\section{ACKNOWLEDGEMENTS}

The authors would like to acknowledge the office of Vice chancellor for research of Hamadan University of Medical Sciences for financial support of this study. Also we would like to thank Mr. Mani Kashani K for his assistance in statistical analysis, Dr Lak-Zadeh M and staff of neonatal ward for their contribution and collaboration.

\section{REFERENCES}

[1] Behrman, R.E., Kliegman, R.M. and Jenson, H.B. (2007) Nelson textbook of pediatrics. 17th Edition, Saunders, Philadelphia.

[2] Feigin, R.D., Chery, J.D., Demmier, G.J. and Kapian, S.L. (2004) Textbook of pediatric infectious diseases. 5th Edition, Saunders, Philadelphia.

[3] Helio, S., Sader, A., Gales, C., et al. (2001) Pathogen frequency and resistance patterns in Brazilian hospitals: Summary of results from three years of the SENTRY antimicrobial surveillance program. The Brazilian Journal of Infectious Diseases, 5(4), 200-214.

[4] Brooks, G., Jawet, E., Butel, J., Morse, S., et al. (2001) Adelberg's medical microbiology. 22nd Edition, McGrawHill, New York.

[5] Zaleznik, D.F. (2005) Hospital-acquired and intravascular device-related infections. In. Kasper, D.L., Braunwald,
E., Fauci, A.S., Hauser, S.L., Longo, D.L. and Jameson, J.L., Harrison's principles of internal medicine, 16th Edition, McGraw-Hill, New York.

[6] Hawkes, C.A. (2000) Antibiotic resistance: A clinicians perspective. Mil Medicine, 165 (7), 43-45.

[7] Steven, M.O. (2000) Mechanisms of bacterial antibiotic resistance. In. Mandel, G.L., Principles and practice of infectious disease, 5th Edition, Churchill Livingstone, London.

[8] Klugman, K.P. and Mahdi, S.A. (1999) Emergence of drug resistance. Infectious Disease Clinics of North America, 13(3), 637-646.

[9] Pavia, M., Nobile, C. and Salpietro, L. (2000) Vancomycin resistance and antibiotic susceptibility of enterococci in raw meat. Journal of Food Protection, 63(7), 912-915.

[10] Binsztein, N., Picandet, A. and Notario, R. (1999) Antimicrobial resistance among species of salmonella, shigella, Escherichia, and aeromonas isolated from children with diarrhea in 7 Argentinean centers. Revista Latinoamericana de Microbiología, 41(3), 121-126.

[11] Yalaz, M., Cetin, H., Akisu, M., Aydemir, S. and Tunger, A. (2006) Neonatal nosocomial sepsis in a level-III NICU: Evaluation of the causative agents and antimicrobial susceptibilities. Turkish Journal of Pediatrics, 48(1), 13-18.

[12] Aurangzeb, B. and Hameed, A. (2003) Neonatal sepsis in hospital- born babies: bacterial isolates and antibiotic susceptibility patterns. Journal of College of Physicians and Surgeons Pakistan, 13(11), 629-632.

[13] Collee, J., Duguide, J. and Fraser, A. (1989) Practical medical microbiology. 13th Edition, Churchill Livingstone, New York.

[14] Bedford, H., Louvois, J., Halket, S., et al. (2001) Meningitis in infancy in England and Wales: follow up at age 5 years. British Medical Journal, 323(7312), 533-536.

[15] Eghbalian, F. and Yousefi, R. (2005) Determining the frequency of the bacterial agents in urinary tract infection in hospitalized patients under 18 years old. Journal of Army university of medical sciences of the I.R.Iran, 3(3), 636-639.

[16] Wenger, J., Hightower, A., Facklam, R., et al. (1990) Bacterial meningitis in the United States. Journal of Infectious Diseases, 162(6), 1316-1323. 